\title{
Health resource utilization for inpatients with COPD treated with nebulized arformoterol or nebulized formoterol
}

This article was published in the following Dove Press journal:

International Journal of COPD

20 June 2017

Number of times this article has been viewed

\author{
Vaidyanathan Ganapathy' \\ Michael D Stensland ${ }^{2}$ \\ 'Sunovion Pharmaceuticals Inc., \\ Marlborough, MA, ${ }^{2}$ Agile Outcomes \\ Research, Inc., Rochester, MN, USA
}

Correspondence: Vaidyanathan Ganapathy

Sunovion Pharmaceuticals Inc., 84 Waterford Drive, Marlborough, MA 01752, USA

Tel +l 7743697123

Email vaidyanathan.ganapathy@sunovion. com
Objective: Arformoterol is the (R,R)-enantiomer of formoterol. Preclinical studies suggest that it is a stronger bronchodilator than the racemic $(\mathrm{R}, \mathrm{R} / \mathrm{S}, \mathrm{S})$-formoterol; however, its potential clinical advantages have not been demonstrated. This study compared the length of stay (LOS), 30-day readmission rates, and doses of rescue medication administered in hospitalized patients with COPD who were treated with nebulized arformoterol or nebulized formoterol.

Methods: This retrospective analysis utilized data from Premier, Inc. (Charlotte, NC, USA), the largest nationwide hospital-based administrative database. COPD patients $\geq 40$ years of age were included if they were hospitalized between January 2011 and July 2014, had no asthma diagnoses, and were treated with nebulized arformoterol or nebulized formoterol. LOS was measured from the day the patients initiated the study medication (index day). Rescue medications were defined as short-acting bronchodilators used from the index day onward. Multivariate statistical models included a random effect for hospital and controlled for patient demographics, hospital characteristics, admission characteristics, prior hospitalizations, comorbidities, pre-index service use, and pre-index medication use.

Results: A total of 7,876 patients received arformoterol, and 3,612 patients received nebulized formoterol. There was no significant difference in 30-day all-cause (arformoterol $=11.9 \%$, formoterol $=12.1 \%$, odds ratio $[\mathrm{OR}]=0.981, P=0.82$ ) or COPD-related hospital readmission rates (arformoterol $=8.0 \%$, formoterol $=8.0 \%, \mathrm{OR}=1.002, P=0.98$ ) after adjusting for covariates. The adjusted mean LOS was significantly shorter for arformoterol-treated vs formoterol-treated patients (4.6 vs 4.9 days, $P=0.039$ ), and arformoterol-treated patients used significantly fewer doses of rescue medications vs formoterol-treated patients (5.9 vs 6.6 doses, $P=0.006$ ).

Conclusion: During inpatient stays, treating with arformoterol instead of nebulized formoterol may lead to shorter LOS and lower rescue medication use.

Keywords: nebulized long-acting bronchodilator agents, patient readmission, length of stay

\section{Introduction}

COPD is the third leading cause of death in the US, and over 10.5 million individuals in the US have been estimated to have COPD. ${ }^{1,2}$ Patients with this progressive disease have persistent symptoms of limited airflow and experience atypical inflammatory reactions to respiratory irritants. ${ }^{3}$ As the disease progresses, patients experience more frequent acute exacerbations that require a change in medication, as well as more severe exacerbations that result in hospitalization. ${ }^{4}$ Exacerbations lead to further progression of COPD and are the main cause of morbidity and mortality in COPD. ${ }^{5,6}$ In the US, the direct costs of COPD have been estimated at $\$ 29.5$ billion per year. ${ }^{7}$ Patients with exacerbations 
incur substantially higher treatment costs, particularly when the exacerbations are severe and require hospitalization, compared with those without any exacerbations. ${ }^{8}$

When hospitalized for acute exacerbations, patients are usually treated with short-acting beta-agonists (SABAs), antibiotics, and systemic corticosteroids. ${ }^{9-11}$ In addition, nebulized treatment appears to be the preferred drug delivery method over hand-held inhalers during inpatient stays. ${ }^{10,12}$ The delivered dose has been shown to be influenced by the type of nebulizer employed. ${ }^{13}$ Although one study found no difference between delivering long-acting beta-agonists (LABAs) by either metered-dose inhalers or nebulizers, ${ }^{14}$ nebulized treatment has been recommended for certain patient populations ${ }^{12}$ and is the most likely route for hospitalized patients. ${ }^{10}$ Based on clinical evidence, initiation of maintenance treatment with long-acting bronchodilators is recommended for hospitalized patients after stabilization and prior to discharge from the hospital. ${ }^{3}$ Not surprisingly, treatment with long-acting bronchodilators in the outpatient setting has been found to reduce future hospital admissions. ${ }^{15}$ When patients with COPD are effectively treated, their symptoms can be minimized and disease progression can be slowed. ${ }^{16}$

The LABAs, arformoterol and formoterol, have both been proven to be efficacious and are available as nebulized treatment agents. ${ }^{17,18}$ Arformoterol is the (R,R)-enantiomer of formoterol, and appears to have more potent bronchodilator properties than racemic (R,R/S,S)-formoterol. ${ }^{19,20}$ However, despite the availability of approved effective nebulized treatments, there is limited comparative evidence between these agents. Results from a clinical trial reported no significant differences between nebulized arformoterol and dry powder inhaler-delivered formoterol when examining traditional efficacy outcomes such as change in forced expiratory volume in 1 second $\left(\mathrm{FEV}_{1}\right)$, symptoms, functional outcomes, and rescue medication use. ${ }^{21}$ The clinical trial was conducted in controlled settings among clinically stable COPD patients in the community - those with unstable respiratory illness or a recent respiratory infection were excluded. This study may not accurately represent patients treated in a real-world setting. Additionally, there is no study to date that has compared the outcomes of arformoterol vs formoterol among patients hospitalized for COPD symptoms, particularly on length of stay (LOS), a common measure of performance and determinant of costs. ${ }^{22}$ The objective of this study was to compare the LOS, 30-day readmission rates (all-cause and COPD-related), and number of doses of rescue medications among inpatients with COPD who were treated with nebulized arformoterol or nebulized formoterol.

\section{Methods}

\section{Study design and database}

This retrospective cohort study used administrative data from Premier, Inc. (Charlotte, NC, USA), the largest hospitalbased, service-level database in the US. The Premier database contains detailed service information from over 500 hospitals for more than 50 million inpatient discharges since the year 2000. The analysis was restricted to hospitalizations between January 1, 2010 and January 31, 2015. This was a retrospective analysis of de-identified data, as designated by the Health Insurance Portability and Accountability Act, ${ }^{23}$ and therefore did not require institutional review board approval.

\section{Inclusion/exclusion criteria}

Patients were included if they had a primary COPD discharge diagnosis (ICD-9-CM 491.xx [chronic bronchitis], 492. xx [emphysema], or 496.xx [chronic airway obstruction, not elsewhere classified]) or a secondary COPD discharge diagnosis with a primary respiratory diagnosis (ICD-9-CM 460.xx-519.xx), were at least 40 years of age, were admitted to the hospital between January 1, 2011 and July 31, 2014 , had an admission with an LOS $\leq 30$ days, and were treated with either arformoterol or formoterol (but not both) during the hospital stay. Patients were excluded if they had an asthma diagnosis (ICD-9-CM 493.xx) or died during the hospitalization. Figure 1 shows the patient flow through the inclusion and exclusion criteria.

\section{Definitions}

The first hospitalization for a patient who met all inclusion and exclusion criteria stated above was designated as the index hospitalization. The index day was defined as the day that the patient initiated the index drug (either arformoterol or formoterol) during the index hospitalization. The baseline period was the 12 -month period preceding the admission month for the index hospitalization. The follow-up period was the 6-month period following the discharge month for the index hospitalization.

The primary outcome variable was the LOS, which was defined as the number of days from the index day (ie, the day of drug initiation) to the discharge day. Because the data truncated dates to month and year only, 30-day allcause readmission was defined as any readmission to the same hospital during the current or next month. Consistent with the patient selection criteria, 30-day COPD-related readmissions were defined as any readmission in the current or next calendar month with a primary COPD diagnosis or 


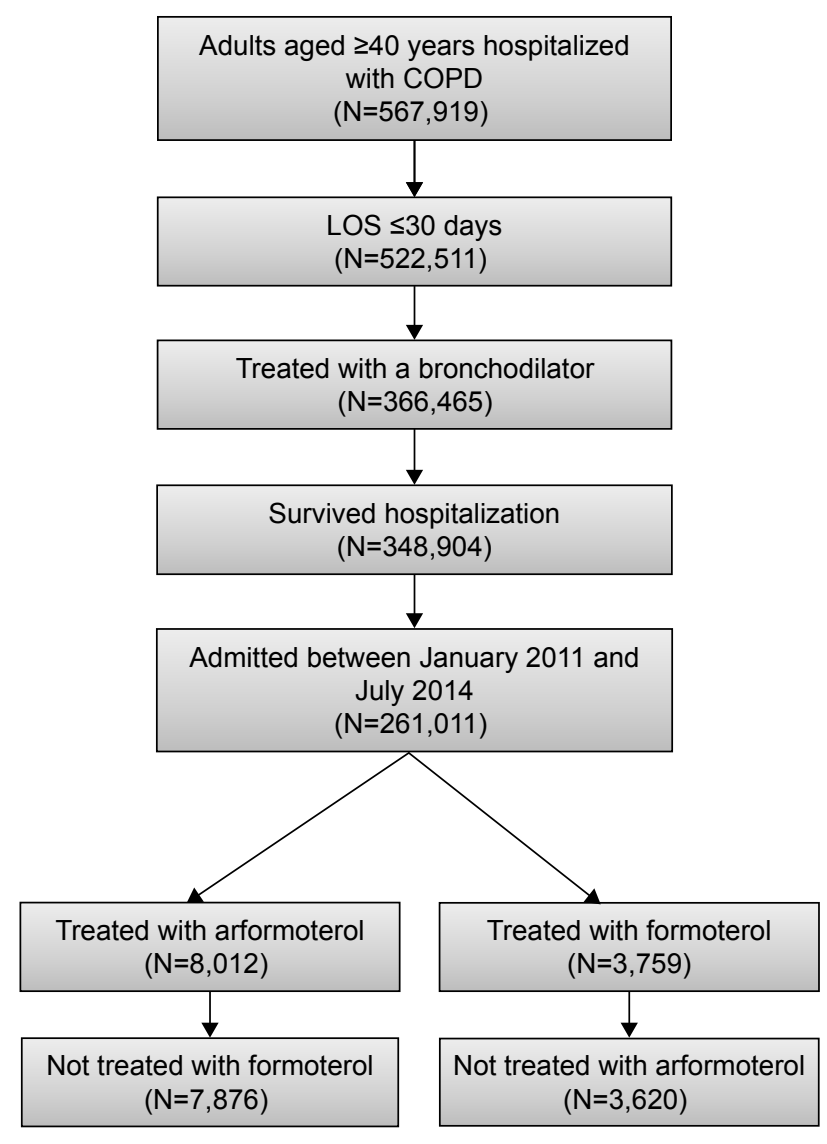

Figure I Patient flow through selection criteria.

Abbreviation: LOS, length of stay.

a secondary COPD diagnosis with a primary respiratory diagnosis. Doses of rescue medication were the number of times a SABA, a short-acting muscarinic agonist (SAMA), or a combination product including a SABA and a SAMA was given during the hospitalization. Doses of rescue medication were counted beginning with the index day.

The definitions of outcome variables were varied in sensitivity analyses to confirm the robustness of the results. LOS was also modeled as the time from admission to discharge rather than index day to discharge. In addition to examining any 30-day readmission, the count of readmissions, both allcause and COPD-related, during the 30 days and 6 months following discharge was also examined.

Multiple background characteristics were used to statistically adjust for any potential differences between the arformoterol and formoterol cohorts. These included patient demographics, hospital characteristics, admission characteristics, prior hospitalizations, and inpatient respiratory services that were used prior to or on the index day (Table 1). In addition, several comorbid conditions were examined including those that have been linked to differential outcomes in COPD, ${ }^{24,25}$ the broader Elixhauser comorbidities, ${ }^{26}$ and several potentially relevant comorbidities for respiratory conditions (Table 2).

\section{Statistical methods}

For all the outcome variables, multivariate generalized linear mixed models (GLIMMIX models) that included a random intercept for hospital were used. All models included all background variables defined in Tables 1 and 2 as covariates. For dichotomous variables (ie, readmission in 30 days), the GLIMMIX models with a binomial distribution and a logit link were used. For count variables (number of rescue doses, LOS, and number of hospitalizations in the 6-month follow-up), the GLIMMIX models with a negative binomial distribution and a log link were used. All results reported are the least square means, which are adjusted for background characteristics. Sensitivity analyses of all outcomes adjusting for concomitant medication use anytime during hospitalization (instead of pre-index period only) were performed. The two-tailed alpha was set at $P=0.05$. Analyses were conducted using SAS version 9.4 (SAS Institute, Cary, NC, USA).

\section{Cost estimates}

To estimate cost implications for differences in LOS, external information was utilized. The Healthcare Cost and Utilization Project reported that the average LOS of all hospitalizations with primary diagnoses of COPD in 2008 was 4.8 days with a reported mean cost per stay of $\$ 7,500 \cdot{ }^{27}$ Dividing the average cost by LOS, the cost per day was estimated to be $\$ 1,562.50$ $(7,500 / 4.8)$. This cost-per-day value was multiplied by the average difference in LOS.

\section{Results}

\section{Patient selection}

The database contained information on 567,919 patients aged $\geq 40$ years who met the COPD diagnostic criteria (including no asthma diagnoses) and who had a hospital admission. The patient flow through selection criteria can be seen in Figure 1. The final cohorts consisted of 11,496 patients from 271 unique hospitals: 7,876 (68.5\%) treated with arformoterol and 3,620 (31.5\%) treated with formoterol.

\section{Patient baseline characteristics}

The baseline characteristics of the patients treated with arformoterol and formoterol can be seen in Table 1. With the large sample size, there were several statistically significant differences between the arformoterol and formoterol cohorts on patient demographics, admission characteristics, prior 
Table I Baseline characteristics

\begin{tabular}{|c|c|c|c|c|c|}
\hline \multirow[t]{2}{*}{ Variable } & \multicolumn{2}{|c|}{ Arformoterol $(\mathrm{N}=7,876)$} & \multicolumn{2}{|c|}{ Formoterol $(\mathrm{N}=3,620)$} & \multirow[t]{2}{*}{$P$-value } \\
\hline & Mean or \% & SD or $n$ & Mean or $\%$ & SD or $n$ & \\
\hline \multicolumn{6}{|l|}{ Demographics } \\
\hline Age (years) & 70.6 & 10.8 & 70.9 & 10.8 & 0.10 \\
\hline Gender (female) & $52.5 \%$ & 4,137 & $52.60 \%$ & $\mathrm{I}, 904$ & 0.94 \\
\hline Marital status & & & & & $<0.001$ \\
\hline Married & $39.0 \%$ & 3,075 & $37.2 \%$ & $\mathrm{I}, 347$ & \\
\hline Single & $50.0 \%$ & 3,941 & $47.9 \%$ & $\mathrm{I}, 733$ & \\
\hline Other & $10.9 \%$ & 860 & $14.9 \%$ & 540 & \\
\hline Race & & & & & $<0.001$ \\
\hline White & $88.1 \%$ & 6,938 & $84.6 \%$ & 3,061 & \\
\hline Black & $6.3 \%$ & 496 & $4.0 \%$ & 143 & \\
\hline Hispanic & $0.3 \%$ & 23 & $0.03 \%$ & I & \\
\hline Other & $5.3 \%$ & 419 & $11.5 \%$ & 415 & \\
\hline \multicolumn{6}{|l|}{ Hospital characteristics } \\
\hline Division (region) & & & & & $<0.001$ \\
\hline East North Central (Midwest) & $14.2 \%$ & 1,116 & $16.9 \%$ & 613 & \\
\hline West North Central (Midwest) & $11.2 \%$ & 879 & $2.6 \%$ & 93 & \\
\hline New England (Northeast) & $6.6 \%$ & 523 & $10.6 \%$ & 385 & \\
\hline Middle Atlantic (Northeast) & $4.2 \%$ & 331 & $2.7 \%$ & 98 & \\
\hline South Atlantic (South) & $25.4 \%$ & 1,998 & $39.6 \%$ & $\mathrm{I}, 435$ & \\
\hline East South Central (South) & $20.7 \%$ & 1,627 & $13.7 \%$ & 497 & \\
\hline West South Central (South) & $15.3 \%$ & $|, 20|$ & $1.5 \%$ & 53 & \\
\hline Mountain (West) & $1.3 \%$ & 103 & $8.4 \%$ & 304 & \\
\hline Pacific (West) & $1.2 \%$ & 98 & $3.9 \%$ & 142 & \\
\hline Urban hospital & $66.1 \%$ & 5,208 & $86.3 \%$ & 3,123 & $<0.001$ \\
\hline Teaching hospital & $27.9 \%$ & 2,195 & $20.9 \%$ & 756 & $<0.001$ \\
\hline Hospital size group (beds) & & & & & $<0.001$ \\
\hline 0-99 & $10.4 \%$ & 818 & $3.6 \%$ & 130 & \\
\hline $100-199$ & $28.3 \%$ & 2,231 & $24.0 \%$ & 868 & \\
\hline $200-299$ & $14.2 \%$ & 1,119 & $27.9 \%$ & 1,010 & \\
\hline $300-399$ & $20.0 \%$ & $\mathrm{I}, 573$ & $20.3 \%$ & 733 & \\
\hline $400-499$ & $7.0 \%$ & 550 & $2.7 \%$ & 97 & \\
\hline $500-599$ & $10.2 \%$ & 801 & $0.5 \%$ & 19 & \\
\hline $600-699$ & $5.3 \%$ & 416 & $6.1 \%$ & 222 & \\
\hline $700+$ & $4.7 \%$ & 368 & $14.9 \%$ & 541 & \\
\hline \multicolumn{6}{|l|}{ Admission characteristics } \\
\hline Payer type & & & & & 0.010 \\
\hline Commercial & $9.0 \%$ & 711 & $10.4 \%$ & 376 & \\
\hline Medicaid & $6.9 \%$ & 543 & $6.7 \%$ & 242 & \\
\hline Medicare & $80.1 \%$ & 6,308 & $78.2 \%$ & 2,830 & \\
\hline Self-insured & $2.4 \%$ & 185 & $2.4 \%$ & 86 & \\
\hline Other & $1.6 \%$ & 129 & $2.4 \%$ & 86 & \\
\hline Admission source & & & & & $<0.001$ \\
\hline Clinical & $4.5 \%$ & 354 & $4.1 \%$ & 148 & \\
\hline Physician & $78.7 \%$ & 6,198 & $80.9 \%$ & 2,930 & \\
\hline Transfer & $12.5 \%$ & 987 & $7.2 \%$ & 260 & \\
\hline Other & $4.3 \%$ & 337 & $7.8 \%$ & 282 & \\
\hline Admission type & & & & & $<0.001$ \\
\hline ER & $79.7 \%$ & 6,274 & $79.1 \%$ & 2,865 & \\
\hline Urgent & $9.1 \%$ & 720 & $14.5 \%$ & 524 & \\
\hline Other & $11.2 \%$ & 882 & $6.4 \%$ & 231 & \\
\hline Admitting physician & & & & & $<0.001$ \\
\hline General & $80.2 \%$ & 6,314 & $84.6 \%$ & 3,064 & \\
\hline Pulmonology & $10.4 \%$ & 822 & $4.1 \%$ & 148 & \\
\hline Other & $9.4 \%$ & 740 & $11.3 \%$ & 408 & \\
\hline
\end{tabular}


Table I (Continued)

\begin{tabular}{|c|c|c|c|c|c|}
\hline \multirow[t]{2}{*}{ Variable } & \multicolumn{2}{|c|}{ Arformoterol $(\mathrm{N}=7,876)$} & \multicolumn{2}{|c|}{ Formoterol $(\mathrm{N}=3,620)$} & \multirow[t]{2}{*}{$P$-value } \\
\hline & Mean or $\%$ & SD or $n$ & Mean or $\%$ & SD or $n$ & \\
\hline APR-DRG severity & 2.7 & 0.8 & 2.8 & 0.8 & 0.18 \\
\hline Primary COPD diagnosis & $49.3 \%$ & 3,885 & $46.6 \%$ & 1,688 & 0.007 \\
\hline Index day' & 2.4 & 2.1 & 2.3 & 2.0 & 0.36 \\
\hline Discharge month ${ }^{2}$ & 37.1 & 12.7 & 37.6 & 12.6 & 0.052 \\
\hline \multicolumn{6}{|l|}{ Prior hospitalizations } \\
\hline Number of prior hospitalizations & 1.0 & 1.6 & 1.0 & 1.6 & 0.81 \\
\hline Number of prior COPD hospitalizations & 0.6 & 1.2 & 0.6 & 1.2 & 0.93 \\
\hline Recent all-cause hospitalization ${ }^{3}$ & $19.5 \%$ & 1,532 & $19.0 \%$ & 687 & 0.55 \\
\hline Recent COPD hospitalization ${ }^{3}$ & $13.3 \%$ & 1,046 & $13.2 \%$ & 478 & 0.91 \\
\hline \multicolumn{6}{|l|}{ Pre-index service use } \\
\hline Arterial line & $0.4 \%$ & 28 & $0.4 \%$ & 13 & 0.98 \\
\hline BiPAP/CPAP & $23.5 \%$ & $\mathrm{I}, 854$ & $28.0 \%$ & 1,013 & $<0.001$ \\
\hline Blood gas assessment & $55.5 \%$ & 4,373 & $58.4 \%$ & 2,114 & 0.004 \\
\hline Intensive care unit & $24.5 \%$ & $\mathrm{I}, 927$ & $26.2 \%$ & 950 & $0.04 I$ \\
\hline Other pulmonary function tests & $5.2 \%$ & 410 & $4.3 \%$ & 154 & 0.028 \\
\hline Other respiratory services & $97.0 \%$ & 7,642 & $98.4 \%$ & 3,561 & $<0.001$ \\
\hline Oxygen therapy & $63.1 \%$ & 4,973 & $61.2 \%$ & 2,217 & 0.05 \\
\hline Spirometry & $4.3 \%$ & 342 & $3.7 \%$ & 132 & 0.08 \\
\hline Ventilator & $13.5 \%$ & 1,060 & $15.4 \%$ & 558 & 0.01 \\
\hline \multicolumn{6}{|l|}{ Pre-index concomitant medications } \\
\hline SABA & $59.2 \%$ & 4,661 & $64.7 \%$ & 2,341 & $<0.001$ \\
\hline SAMA & $32.6 \%$ & 2,570 & $36.7 \%$ & ।,328 & $<0.001$ \\
\hline LAMA & $26.8 \%$ & 2,108 & $19.6 \%$ & 709 & $<0.001$ \\
\hline ICS & $61.4 \%$ & 4,832 & $73.4 \%$ & 2,657 & $<0.001$ \\
\hline LABA + ICS & $15.3 \%$ & $\mathrm{I}, 205$ & $16.6 \%$ & 601 & 0.07 \\
\hline SABA + SAMA & $56.3 \%$ & 4,432 & $60.0 \%$ & $2,|7|$ & $<0.001$ \\
\hline Systemic corticosteroids & $85.6 \%$ & 6,740 & $86.6 \%$ & 3,135 & 0.14 \\
\hline Methylxanthines & $6.9 \%$ & 546 & $6.6 \%$ & 237 & 0.45 \\
\hline Phosphodiesterase-4 inhibitors & $2.3 \%$ & 177 & $2.1 \%$ & 75 & 0.55 \\
\hline Nicotine treatment & $10.8 \%$ & 847 & $10.8 \%$ & 390 & 0.98 \\
\hline
\end{tabular}

Notes: 'Coded as the service day in which patients began receiving either arformoterol or nebulized formoterol. ${ }^{2}$ Coded as an integer indexing the study month starting with January, $2010=1$ and ending with January, $2015=61$. ${ }^{3}$ Recent was defined as the 30 days prior to the index admission. Bold figures represent statistically significant values. Abbreviations: ER, emergency room; APR-DRG, All Patients Refined Diagnosis Related Groups; BiPAP, bilevel positive airway pressure; CPAP, continuous positive airway pressure; SABA, short-acting beta-agonist; SAMA, short-acting muscarinic agonist; LAMA, long-acting muscarinic agonist; ICS, inhaled corticosteroids; LABA, long-acting beta-agonist.

Table 2 Comorbidities

\begin{tabular}{|c|c|c|c|c|c|}
\hline \multirow[t]{2}{*}{ Variable } & \multicolumn{2}{|c|}{ Arformoterol $(\mathrm{N}=7,876)$} & \multicolumn{2}{|c|}{ Formoterol $(\mathrm{N}=3,620)$} & \multirow[t]{2}{*}{$P$-value } \\
\hline & Mean or \% & $\overline{S D}$ or $n$ & Mean or \% & $\overline{S D}$ or $n$ & \\
\hline \multicolumn{6}{|l|}{ Comorbidities } \\
\hline Charlson Comorbidity Index & 2.4 & 1.7 & 2.3 & 1.6 & 0.23 \\
\hline COPD comorbidity count & 2.9 & 1.9 & 2.9 & 1.9 & 0.25 \\
\hline \multicolumn{6}{|l|}{ COPD-relevant comorbidities } \\
\hline Allergic rhinitis & $1.8 \%$ & 145 & $1.0 \%$ & 37 & 0.001 \\
\hline Congestive heart failure & $32.0 \%$ & 2,522 & $29.2 \%$ & $\mathrm{I}, 057$ & 0.002 \\
\hline Coronary heart disease & $34.3 \%$ & 2,705 & $33.4 \%$ & $\mathrm{I}, 209$ & 0.32 \\
\hline Diabetes & $28.6 \%$ & 2,253 & $28.7 \%$ & $\mathrm{I}, 038$ & 0.94 \\
\hline GERD & $24.1 \%$ & 1,897 & $24.1 \%$ & 872 & 1.00 \\
\hline Hypercholesterolemia & $38.8 \%$ & 3,052 & $40.0 \%$ & $\mathrm{I}, 449$ & 0.19 \\
\hline Hypertension & $65.9 \%$ & 5,193 & $64.5 \%$ & 2,335 & 0.13 \\
\hline Obesity & $15.7 \%$ & 1,240 & $15.6 \%$ & 565 & 0.85 \\
\hline Osteoarthritis & $10.0 \%$ & 788 & $9.0 \%$ & 324 & 0.08 \\
\hline Osteoporosis & $6.8 \%$ & 537 & $7.0 \%$ & 255 & 0.66 \\
\hline Peptic ulcer & $0.6 \%$ & 50 & $0.8 \%$ & 28 & 0.40 \\
\hline Peripheral vascular disease & $10.3 \%$ & 810 & $10.7 \%$ & 386 & 0.54 \\
\hline Sleep apnea & $16.1 \%$ & $|, 27|$ & $17.2 \%$ & 621 & 0.17 \\
\hline Stroke & $7.6 \%$ & 600 & $7.4 \%$ & 267 & 0.65 \\
\hline
\end{tabular}


Table 2 (Continued)

\begin{tabular}{|c|c|c|c|c|c|}
\hline \multirow[t]{2}{*}{ Variable } & \multicolumn{2}{|c|}{ Arformoterol $(\mathrm{N}=7,876)$} & \multicolumn{2}{|c|}{ Formoterol $(\mathrm{N}=3,620)$} & \multirow[t]{2}{*}{$P$-value } \\
\hline & Mean or \% & SD or $n$ & Mean or $\%$ & SD or $n$ & \\
\hline \multicolumn{6}{|l|}{ Elixhauser comorbidities' } \\
\hline AIDS/HIV & $0.1 \%$ & 11 & $0.1 \%$ & 4 & 0.69 \\
\hline Alcohol abuse & $4.1 \%$ & 320 & $3.6 \%$ & 130 & 0.23 \\
\hline Anemia deficiency & $4.3 \%$ & 340 & $4.8 \%$ & 174 & 0.24 \\
\hline Blood loss anemia & $0.6 \%$ & 44 & $0.6 \%$ & 22 & 0.75 \\
\hline Cardiac arrhythmias & $31.8 \%$ & 2,508 & $33.8 \%$ & 1,223 & 0.039 \\
\hline Coagulopathy & $4.7 \%$ & 366 & $5.0 \%$ & $|8|$ & 0.41 \\
\hline Depression & $18.6 \%$ & $\mathrm{I}, 463$ & $18.8 \%$ & 682 & 0.74 \\
\hline Drug abuse & $3.0 \%$ & 236 & $2.2 \%$ & 78 & 0.010 \\
\hline Fluid and electrolyte disorders & $34.1 \%$ & 2,688 & $34.8 \%$ & 1,258 & 0.51 \\
\hline Hypothyroidism & $15.1 \%$ & $\mathrm{I}, 188$ & $16.5 \%$ & 596 & 0.06 \\
\hline Liver disease & $3.3 \%$ & 256 & $2.8 \%$ & 101 & 0.19 \\
\hline Lymphoma & $0.8 \%$ & 59 & $1.0 \%$ & 37 & 0.14 \\
\hline Metastatic cancer & $2.3 \%$ & 179 & $2.5 \%$ & 92 & 0.38 \\
\hline Other neurological disorders & $8.2 \%$ & 645 & $7.5 \%$ & 271 & 0.20 \\
\hline Paralysis & $0.5 \%$ & 38 & $0.4 \%$ & 16 & 0.77 \\
\hline Psychosis & $2.3 \%$ & 181 & $1.9 \%$ & 69 & 0.18 \\
\hline Pulmonary circulation disorders & $12.8 \%$ & $\mathrm{I}, 007$ & $13.7 \%$ & 495 & 0.19 \\
\hline Renal failure & $15.9 \%$ & 1,248 & $15.1 \%$ & 548 & 0.33 \\
\hline Rheumatoid arthritis & $3.3 \%$ & 262 & $4.2 \%$ & 152 & 0.020 \\
\hline Solid tumor without metastasis & $7.1 \%$ & 562 & $6.0 \%$ & 217 & 0.024 \\
\hline Valvular disease & $6.3 \%$ & 495 & $8.6 \%$ & 312 & $<0.001$ \\
\hline Weight loss & $10.5 \%$ & 824 & $8.1 \%$ & 293 & $<0.001$ \\
\hline \multicolumn{6}{|l|}{ Respiratory comorbidities } \\
\hline Anxiety & $24.4 \%$ & 1,920 & $23.8 \%$ & 862 & 0.51 \\
\hline Influenza/respiratory infection & $3.3 \%$ & 258 & $3.7 \%$ & 134 & 0.24 \\
\hline Lung cancer & $5.1 \%$ & 400 & $4.3 \%$ & 156 & 0.07 \\
\hline Pneumonia & $39.5 \%$ & 3,112 & $39.2 \%$ & 1,418 & 0.73 \\
\hline Sinusitis & $1.7 \%$ & 134 & $1.3 \%$ & 47 & 0.11 \\
\hline Tobacco use & $30.1 \%$ & 2,369 & $29.9 \%$ & 1,083 & 0.86 \\
\hline
\end{tabular}

Notes: 'Comorbidities from Elixhauser that were not previously categorized as COPD-relevant. Bold figures represent statistically significant values. Abbreviation: GERD, gastroesophageal reflux disease.

hospitalization, and pre-index service use, but the magnitude of the differences was generally small ( $<5 \%$ difference). However, some differences in hospital characteristics (region, urban setting [66.1\% vs 86.3\%], and size based on number of beds) and prior medication use of arformoterol and formoterol cohorts (long-acting muscarinic agonist: $26.8 \%$ vs $19.6 \%$ and inhaled corticosteroids: $61.4 \%$ vs $73.4 \%$, respectively) were larger. There was no difference in the number of prior hospitalizations or All Patients Refined Diagnosis Related Groups severity score between the two cohorts. While both cohorts had similar Charlson Comorbidity Index scores, there were some significant differences in specific comorbidities (Table 2).

\section{Outcomes}

Figure 2 shows the LOS by index medication. After adjusting for baseline characteristics, the adjusted mean post-index LOS was significantly shorter for arformoterol-treated vs formoterol-treated patients ( 4.6 vs 4.9 days, $P=0.039$ ). As seen in Figure 3, a higher percentage of patients who were treated with arformoterol were discharged within 4 days of index medication initiation compared to patients treated with formoterol (46.7\% vs 42.7\%). The LOS difference was the same after adjusting for concomitant medication use anytime during

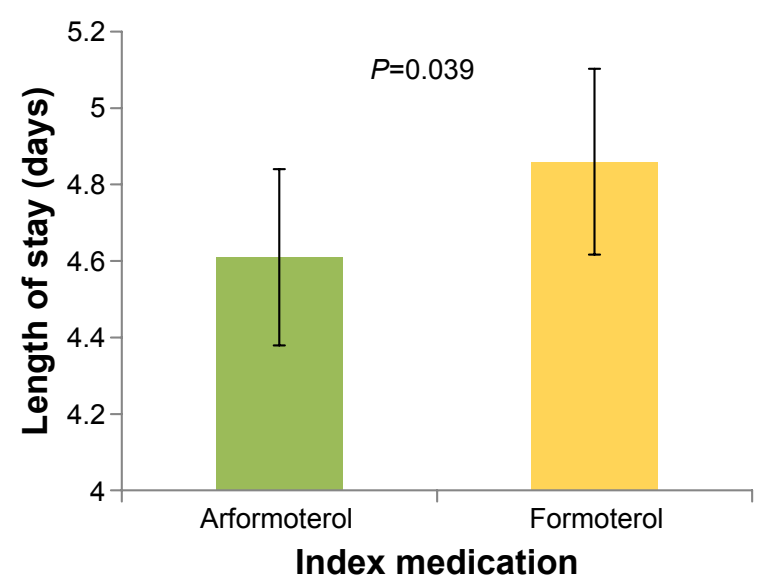

Figure 2 Length of stay following arformoterol or formoterol initiation. Notes: Error bars represent $95 \%$ confidence intervals. Results were similar, but became marginally significant $(P=0.06)$, when the full length of stay for the hospitalization was used instead of length of stay from the start of the index medication. 




Figure 3 Percent of patients discharged by day after index medication initiation.

hospitalization (instead of pre-index), and the difference was marginally significant ( 4.7 vs 4.9 days, $P=0.08$ ). Multiplying the 0.3 difference in LOS from the primary LOS comparison by the average cost per day of $\$ 1,562.50$ yielded an estimated cost difference of $\$ 469$ per patient.

After adjusting for baseline characteristics, there was no significant difference in 30-day all-cause readmission rates $(11.9 \%$ arformoterol vs $12.1 \%$ formoterol, odds ratio $[\mathrm{OR}]=0.981, P=0.82$ ). There was also no significant difference in 30-day COPD-related readmission rates after adjusting for covariates $(8.0 \%$ arformoterol vs $8.0 \%$ formoterol, $\mathrm{OR}=1.002$, $P=0.98)$. These results were confirmed by sensitivity analyses that showed no significant difference between arformoterol and formoterol on the number of readmissions $(0.34$ for arformoterol and 0.35 for formoterol, $P=0.44$ ) and number of COPD-related readmissions ( 0.20 for arformoterol and 0.21 for formoterol, $P=0.34$ ) during the 6-month follow-up period.

Figure 4 gives the doses of rescue medications used for each index treatment. Patients treated with arformoterol



Figure 4 Doses of rescue medication after index medication initiation. Note: Error bars represent $95 \%$ confidence intervals. used significantly fewer doses of rescue medications after the index day than patients treated with formoterol (5.9 vs 6.6 doses, $P=0.006$ ). This difference remained similar and statistically significant after replacing pre-index by any-time concomitant medication use in the regression model (5.8 vs 6.3 doses, $P=0.035$ ).

\section{Discussion}

Nebulized arformoterol $15 \mu \mathrm{g}$ and formoterol $20 \mu \mathrm{g}$ inhalation solutions are two nebulized long-acting bronchodilator treatments that are commonly used in hospitals for the management of COPD. A comparative analysis of the realworld outcomes of these two drugs in hospitalized COPD patients has not been done before. This analysis examined if the superior bronchodilator properties of arformoterol over formoterol translated into real-world benefits in health care resource utilization related to hospital LOS, use of shortacting agents, and a reduction in hospital readmissions for patients admitted for an acute exacerbation of COPD. The data source used for this analysis is a very large hospital claims database not restricted by any provider or payer type, and is nationally representative of hospitalized COPD patients. ${ }^{28-31}$ The analysis reported in this paper showed that patients treated with nebulized arformoterol may have shorter LOS as compared to patients treated with nebulized formoterol. Arformoterol-treated inpatients also used fewer rescue medications, a result that was robust as revealed by further sensitivity analysis. A preclinical study reported that the (R,R-)enantiomer (ie, arformoterol) inhibited both histamine and antigen-induced bronchoconstriction with a greater potency than racemic formoterol. ${ }^{19,20,32}$ While preclinical studies have found that arformoterol acts as a more potent bronchodilator than racemic formoterol, to our knowledge, this is the first study to identify the potential advantage in a clinical population with COPD.

In addition, a recent retrospective cohort study using commercial health care insurance claims reported lower hospitalization costs for arformoterol-treated patients with COPD who were hospitalized compared to formoterol patients who were hospitalized. ${ }^{15}$ Assuming that a shorter LOS corresponds with lower hospital costs, these findings are consistent with the current study. While none of these previously published studies are directly comparable to the current research, the findings are consistent.

A randomized controlled trial in patients with COPD ${ }^{21}$ compared outcomes over a 6-month period for patients treated with formoterol $12 \mu \mathrm{g}$ delivered via a dry powder inhaler $(n=147)$ to that of patients treated with arformoterol $15 \mu \mathrm{g}(\mathrm{n}=149)$ or arformoterol $25 \mu \mathrm{g}(\mathrm{n}=147)$ delivered 
via a nebulizer. In this well-controlled clinical trial, the arformoterol- and formoterol-treated patients had similar improvements in $\mathrm{FEV}_{1}$, symptoms, functional outcomes, and rescue medication use. However, the study reported significantly higher rate of event-defined exacerbations for the arformoterol-treated patients. ${ }^{21}$ While the Hanania et al study $^{21}$ was randomized and had better internal validity to establish inferences about clinical and patient-reported outcomes, the study was not adequately powered to make meaningful inferences about exacerbation events relative to the previously published retrospective analyses of large claims databases. A comparative randomized clinical trial with a much larger sample size may have helped detect differences, if any, with greater confidence.

In the administrative database analysis, measures of potential adverse events of the medications were not available. In the pivotal trials of arformoterol, the incidence of adverse events or COPD exacerbations was not different from that of placebo. Long-term safety studies of arformoterol had also shown that the medication was very well tolerated in COPD. ${ }^{33,34}$ Although head-to-head comparison with nebulized formoterol was not available, the 6-month efficacy and safety study that compared nebulized arformoterol $15 \mu \mathrm{g}$ with formoterol $12 \mu \mathrm{g}$ delivered via a dry powder inhaler found that the incidence of adverse events was similar between these $^{\text {products. }}{ }^{21}$

While absolute differences found in this study in LOS and doses of rescue medications were not large, the differences could be meaningful at the population level, considering that the expenditures associated with hospitalization represent more than $70 \%$ of all COPD-related medical care costs. ${ }^{35}$ The difference of 0.3 days in LOS found in this study implied a potential cost savings of $\$ 469$ per each inpatient treated with arformoterol instead of formoterol. For a hospital with 500 COPD discharges in a year, this would be a cost savings of $\$ 234,500(500 \times \$ 469)$ per year.

\section{Limitations}

The data used in this analysis were collected for administrative and not research purposes. Administrative data allow for observation without intervention of usual clinical care, but the diagnoses are less accurate than in clinical research. Although multivariate regression models were used to adjust for many background differences, unmeasured differences between arformoterol- and formoterol-treated patients could have confounded the results. Thirty-day readmissions were defined based on a readmission in the current or next calendar month because the data only included month and year (not day) of admission. After exiting the hospital, there were no differences between the two medication cohorts in readmission rates, but information about the treatments patients received outside the hospital were not available in the database. After hospital discharge, patients may have switched treatments, which could have potentially obscured differences in readmission rates between patients treated with formoterol or arformoterol.

\section{Conclusion}

This study found that inpatients with COPD treated with nebulized arformoterol had a shorter LOS and used fewer doses of rescue medications than patients treated with nebulized formoterol, which may lead to cost savings. Both arformoterol and formoterol are effective nebulized LABAs for COPD treatment, but there is some preclinical evidence that arformoterol may have a more potent bronchodilator effect. While arformoterol was associated with a shorter LOS and fewer doses of rescue medications in this study, 30-day readmission rates were similar for patients treated with arformoterol and formoterol. Large-scale, randomized, comparative-effectiveness studies are needed to confirm these findings.

\section{Acknowledgment}

This study was funded by Sunovion Pharmaceuticals Inc.

\section{Disclosure}

Vaidyanathan Ganapathy is a full-time employee of Sunovion Pharmaceuticals Inc. Michael D Stensland is a full-time employee and the sole owner of Agile Outcomes Research, Inc., a firm that was hired by Sunovion Pharmaceuticals Inc. to complete this research. The authors report no other conflict of interest in this work.

\section{References}

1. Mannino DM. COPD: epidemiology, prevalence, morbidity and mortality, and disease heterogeneity. Chest. 2002;121(5 Suppl):121S-126S.

2. Mannino DM, Homa DM, Akinbami LJ, Ford ES, Redd SC. Chronic obstructive pulmonary disease surveillance - United States, 1971-2000. MMWR Surveill Summ. 2002;51(6):1-16.

3. Global Initiative for Chronic Obstructive Lung Disease. GOLD 2017 Global Strategy for the Diagnosis, Management and Prevention of COPD. 2017. Available from: http://goldcopd.org/gold-2017-global-strategydiagnosis-management-prevention-copd/. Accessed December 15, 2016.

4. Kessler R, Faller M, Fourgaut G, Mennecier B, Weitzenblum E. Predictive factors of hospitalization for acute exacerbation in a series of 64 patients with chronic obstructive pulmonary disease. Am J Respir Crit Care Med. 1999;159(1):158-164.

5. Standards for the diagnosis and care of patients with chronic obstructive pulmonary disease. American Thoracic Society. Am J Respir Crit Care Med. 1995;152(5 Pt 2):S77-S121. 
6. Hurst JR, Wedzicha JA. Chronic obstructive pulmonary disease: the clinical management of an acute exacerbation. Postgrad Med J. 2004;80(947):497-505.

7. National Heart Lung and Blood Institute. Morbidity and Mortality: 2009 Chart Book on Cardiovascular, Lung, and Blood Diseases. 2009. Available from: https://ecopmc.files.wordpress.com/2012/04/2009_ chartbook.pdf. Accessed September 12, 2016

8. Pasquale MK, Sun SX, Song F, Hartnett HJ, Stemkowski SA. Impact of exacerbations on health care cost and resource utilization in chronic obstructive pulmonary disease patients with chronic bronchitis from a predominantly Medicare population. Int J Chron Obstruct Pulmon Dis. 2012;7:757-764.

9. Lindenauer PK, Pekow P, Gao S, Crawford AS, Gutierrez B, Benjamin EM. Quality of care for patients hospitalized for acute exacerbations of chronic obstructive pulmonary disease. Ann Intern Med. 2006;144(12):894-903.

10. Amin A, Bollu VK, Stensland MD, Netzer L, Ganapathy V. Treatment patterns for patients hospitalized with acute exacerbations of chronic obstructive pulmonary disease. Am J Health Syst Pharm. In press 2017.

11. Chow L, Parulekar AD, Hanania NA. Hospital management of acute exacerbations of chronic obstructive pulmonary disease. J Hosp Med. 2015; 10(5):328-339.

12. Dhand R, Dolovich M, Chipps B, Myers TR, Restrepo R, Farrar JR. The role of nebulized therapy in the management of COPD: evidence and recommendations. COPD. 2012;9(1):58-72.

13. Buttini F, Rossi I, Di Cuia M, et al. Combinations of colistin solutions and nebulisers for lung infection management in cystic fibrosis patients. Int J Pharm. 2016;502(1-2):242-248.

14. Turner MO, Patel A, Ginsburg S, FitzGerald JM. Bronchodilator delivery in acute airflow obstruction. A meta-analysis. Arch Intern Med. 1997;157(15):1736-1744.

15. Chen YJ, Makin C, Bollu VK, Navaie M, Celli BR. Exacerbations, health services utilization, and costs in commercially-insured COPD patients treated with nebulized long-acting $\beta 2$-agonists. J Med Econ. 2016 19(1):11-20.

16. Rodríguez-Roisin R. The airway pathophysiology of COPD: implications for treatment. COPD. 2005;2(2):253-262.

17. Aalbers R, Ayres J, Backer V, et al. Formoterol in patients with chronic obstructive pulmonary disease: a randomized, controlled, 3-month trial Eur Respir J. 2002;19(5):936-943.

18. Baumgartner RA, Hanania NA, Calhoun WJ, Sahn SA, Sciarappa K, Hanrahan JP. Nebulized arformoterol in patients with COPD: a 12-week, multicenter, randomized, double-blind, double-dummy, placebo- and active-controlled trial. Clin Ther. 2007;29(2):261-278.

19. King P. Role of arformoterol in the management of COPD. Int J Chron Obstruct Pulmon Dis. 2008;3(3):385-391.

20. Handley DA, Senanayake CH, Dutczak W, et al. Biological actions of formoterol isomers. Pulm Pharmacol Ther. 2002;15(2):135-145.

21. Hanania NA, Donohue JF, Nelson H, et al. The safety and efficacy of arformoterol and formoterol in COPD. COPD. 2010;7(1):17-31.
22. Thomas JW, Guire KE, Horvat GG. Is patient length of stay related to quality of care? Hosp Health Serv Adm. 1997;42(4):489-507.

23. United States Congress. Health Insurance Portability and Accountability Act of 1996. 1996. Available from: http://www.gpo.gov/fdsys/pkg/ PLAW-104publ191/html/PLAW-104publ191.htm. Accessed September $10,2016$.

24. Putcha N, Han MK, Martinez CH, et al; the COPDGene ${ }^{\circledR}$ Investigators. Comorbidities of COPD have a major impact on clinical outcomes, particularly in African Americans. Chronic Obstruct Pulm Dis. 2014;1(1):105-114.

25. Putcha N, Puhan MA, Drummond MB, et al. A simplified score to quantify comorbidity in COPD. PLoS One. 2014;9(12):e114438.

26. Quan H, Sundararajan V, Halfon P, et al. Coding algorithms for defining comorbidities in ICD-9-CM and ICD-10 administrative data. Med Care. 2005;43(11):1130-1139.

27. Wier LM, Elixhauser A, Pfuntner A, Au DH. Overview of hospitalizations among patients with COPD, 2008. 2011. Available from: http:// www.ncbi.nlm.nih.gov/books/NBK53969/?report=printable. Accessed September 10, 2016

28. Bollu V, Ernst FR, Karafilidis J, Rajagopalan K, Robinson SB, Braman SS. Hospital readmissions following initiation of nebulized arformoterol tartrate or nebulized short-acting beta-agonists among inpatients treated for COPD. Int J Chron Obstruct Pulmon Dis. 2013;8:631-639.

29. Lindenauer PK, Shieh MS, Pekow PS, Stefan MS. Use and outcomes associated with long-acting bronchodilators among patients hospitalized for chronic obstructive pulmonary disease. Ann Am Thorac Soc. 2014;11(8):1186-1194

30. Snider JT, Jena AB, Linthicum MT, et al. Effect of hospital use of oral nutritional supplementation on length of stay, hospital cost, and 30-day readmissions among Medicare patients with COPD. Chest. 2015; 147(6):1477-1484.

31. Premier, Inc. Premier Research Services creates insights through data. 2017. Available from: https:/www.premierinc.com/transforminghealthcare/healthcare-performance-improvement/premier-researchservices/. Accessed February 7, 2017.

32. Mhanna MJ, Koester JF, Cohn RC. Effects of (r,r)- and (r,r/s,s)formoterol on airway relaxation and contraction in an experimental rat model. Curr Ther Res Clin Exp. 2007;68(4):249-261.

33. Donohue JF, Hanania NA, Make B, et al. One-year safety and efficacy study of arformoterol tartrate in patients with moderate to severe COPD. Chest. 2014;146(6):1531-1542.

34. Donohue JF, Hanania NA, Sciarappa KA, et al. Arformoterol and salmeterol in the treatment of chronic obstructive pulmonary disease: a one year evaluation of safety and tolerance. Ther Adv Respir Dis. 2008 2(2):37-48.

35. Sullivan SD, Ramsey SD, Lee TA. The economic burden of COPD. Chest. 2000;117(2 Suppl):5S-9S.
International Journal of COPD

\section{Publish your work in this journal}

The International Journal of COPD is an international, peer-reviewed journal of therapeutics and pharmacology focusing on concise rapid reporting of clinical studies and reviews in COPD. Special focus is given to the pathophysiological processes underlying the disease, intervention programs, patient focused education, and self management protocols.

\section{Dovepress}

This journal is indexed on PubMed Central, MedLine and CAS. The manuscript management system is completely online and includes a very quick and fair peer-review system, which is all easy to use. Visi http://www.dovepress.com/testimonials.php to read real quotes from published authors. 